\title{
Incidence of Type 2 Diabetes Mellitus among Emirati Residents in Ajman, United Arab Emirates
}

\author{
Jayadevan Sreedharan ${ }^{1, *}$, Jayakumary Muttappallymyalii ${ }^{2}$, Shatha al Sharbatti ${ }^{2}$, Sana Hassoun ${ }^{3}$, Rawda Safadi ${ }^{3}$, \\ lehab Abderahman ${ }^{4}$, Wathib Abdulsamad Hameed ${ }^{5}$, Abdul Mohsen Ibrahim ${ }^{6}$, Mohamed Tahir Takana ${ }^{7}$, \\ Ahmad Mohammad Fouda ${ }^{8}$
}

'Statistical Support Facility, Gulf Medical University, Ajman, UAE

${ }^{2}$ Department of Community Medicine, Gulf Medical University, Ajman, UAE

${ }^{3}$ Primary Health Care, Ministry of Health, Ajman Medical District, UAE

${ }^{4}$ Al Madhina Health Center, Ministry of Health, Ajman Medical District, UAE

${ }^{5}$ Al Musheref Health Center, Ministry of Health, Ajman Medical District, UAE

${ }^{6}$ Al Manama Health Center, Ministry of Health, Ajman Medical District, UAE

${ }^{7}$ Mental Health Clinic, Ministry of Health, Ajman Medical District, UAE

${ }^{8}$ Muzeireh Health Center, Ministry of Health, Ajman Medical District, UAE

Background: Diabetes mellitus (DM), particularly type-2 is a major public health concern worldwide. Not much information is available with regard to the incidence of DM in United Arab Emirates (UAE). This study aimed at determining the incidence rate of diabetes mellitus among Emirati population in Ajman, UAE. This is a retrospective cohort study.

Methods: This study was conducted in all primary health care centers and Shaikh Khalifa and GMC Hospitals, Ajman, UAE where the Emirati population primarily go for diagnosis and treatment. The incident cases of diabetes mellitus were collected during the period 2010 January to December.

Results: A total of 158 cases newly detected in 2010, 54 were among non-Emiratis and one was type-1 diabetes. Eliminating these, the remaining 101 were included in the analysis. The age of the patients ranged from 23 years to 78 years; 35 (34.7\%) males and 66 (65.3\%) were females. The overall incidence observed was 4.8/1,000 person-years (PY) with a female predominance of 6.3/1,000 PY against incidence among males of 3.3/1,000 PY. With regard to age specific incidence rate among males, it increases with age till 60 years and then showed a decreasing trend. Among females also the same trend was observed but not as similar to males.

Conclusion: The highest incidence rate was observed in the 55-59 age group among males, 23.4/1,000 PY and females, 32.4/1,000 PY. Among males the incidence rate was much less compared to females in - the age groups older than 59 years.

Keywords: Incidence; Diabetes Mellitus; Ajman; United Arab Emirates 


\section{INTRODUCTION}

Diabetes mellitus (DM) is one of the most common chronic metabolic diseases, which is on the rise globally. ${ }^{1-3)}$ The DM prevalence for all age groups worldwide was estimated to be $2.8 \%$ in 2000 and projected to be $4.4 \%$ by 2030 . During this period, the total number of people with DM is expected to rise from 171 million to 366 million. ${ }^{4)}$ Several explanations have been provided for the increase in DM-prevalence, such as population growth, aging, urbanization, increasing obesity prevalence, and physical inactivity. ${ }^{5)}$

Diabetes poses a challenge not only to those living with the disease, ${ }^{6)}$ but also to their families, communities, and the health care system. ${ }^{7-9)}$ Monitoring the DM prevalence and incidence trend is important for assessing the national burden of the disease to describe the impact of risk factors, develop interventions, and project needs for future health services. ${ }^{4,10)}$

The states in the Co-operation Council for the Arab States of the Gulf (GCC) have some of the highest rates of type 2 DM in the world. Five of the International Diabetes Federation's top ten countries for DM prevalence in 2011 and projected prevalence in 2030 are in this region. ${ }^{11)}$ The recent and rapid socioeconomic development of the GCC countries has been associated with this rising prevalence. ${ }^{12)}$ According to the International Diabetes Federation, the number of people with DM in its Middle East-North Africa region will increase to $83 \%$ by 2030. ${ }^{11)}$

In the United Arab Emirates (UAE), the DM prevalence has reached $24 \%$ and $17.4 \%$ among citizens and expatriates, ${ }^{13)}$ respectively. The DM prevalence in the UAE was ranked to be the 2nd highest in the world (19.5\%) in 2007, and the expected prevalence for 2025 is $21.9 \%{ }^{12)}$ The UAE has developed a National Diabetes Care Continuum program with guidelines to combat this disease. ${ }^{13)}$ Based on a population study conducted in $\mathrm{Al}$ Ain, in the UAE, the age-standardized prevalence rates for DM (diagnosed and undiagnosed) and pre-diabetes among people aged $30-64$ years were $29.0 \%$ and $24.2 \%$, respectively. ${ }^{14}$ No published data are available about the age-standardized incidence rates of DM in the UAE. Such data are important, because information on incidence will help plan specific preventive and control strategies, and will enhance our knowledge about the profile of this disease in the UAE. Therefore, this study was conducted to determine the age and gender specific incidence rate of DM among nationals in Ajman Medical District in 2010.

\section{METHODS}

The study population consisted of Emirati residents of Ajman, UAE. The total population of Ajman, UAE as per 2005 census was 206,997 (men, 131,684; women, 75,313). Among this,
39,231 were Emiratis (men, 20,155; women, 19,076) and the remaining were other nationals (11,529 males and 56,237 females). Participants of both genders and all ages were represented in this study population. The age and gender distribution of the Ajman population (estimated for 2010 using the geometric growth method) is shown in Table 1. All participants diagnosed with DM during 2010 were studied using a retrospective cohort approach. Health care services for the target population were mainly provided through 5 primary healthcare centers and 2 general hospitals (Sheikh Khalifa Hospital and GMC Hospital, Ajman) in Ajman during the study period, and most of the diabetic patients were presumed to be managed at these sites.

The data were collected by using a proforma that was prepared by the team of investigators. The draft proforma was pilot tested and then finalized. Every copy of the research proforma was allocated a code number to identify the primary health care center. The pro forma consisted of the domains, such as socio-demographic characteristics, clinical data, biochemical parameters, and mode of management. The Emirates or health insurance identification number of the nationals and expatriates were recorded to eliminate duplication.

Approval from the ethics and research committees of Gulf Medical University and Ministry of Health was obtained before commencing this study, and a prior approval was sought from the director of Ajman Medical District to conduct the study at primary health care centers (PHC). Participants were not identified by their names, and any information that could reveal the identity of the subjects was not recorded on the proforma. Furthermore, confidentiality of the research data was maintained and anonymity was preserved. Confidentiality was maintained

Table 1. Age and gender distribution of Emirati residents in Ajman, United Arab Emirates

\begin{tabular}{lrrr}
\hline Age group (y) & Males $(n)$ & Females $(n)$ & Total $(n)$ \\
\hline $0-4$ & 2,864 & 2,689 & 5,553 \\
$5-9$ & 2,686 & 2,550 & 5,236 \\
$10-14$ & 2,788 & 2,565 & 5,353 \\
$15-19$ & 2,977 & 2,731 & 5,708 \\
$20-24$ & 2,685 & 2,751 & 5,436 \\
$25-29$ & 2,143 & 2,178 & 4,321 \\
$30-34$ & 1,315 & 1,331 & 2,646 \\
$35-39$ & 1,075 & 1,131 & 2,206 \\
$40-44$ & 751 & 939 & 1,690 \\
$45-49$ & 750 & 705 & 1,455 \\
$50-54$ & 582 & 470 & 1,052 \\
$55-59$ & 398 & 309 & 707 \\
$60-64$ & 320 & 226 & 546 \\
$65-69$ & 273 & 160 & 433 \\
$70-74$ & 203 & 132 & 335 \\
$75-79$ & 99 & 67 & 166 \\
$\geq 80$ & 91 & 66 & 157 \\
Total & 22,000 & 21,000 & 43,000 \\
\hline
\end{tabular}


by maintaining all research documents at the statistical support facility for 3 years, and only the researchers, ethics and research committee members, and statistical support facility members had access to the data with appropriate regulatory sight. Any information that can be used to reveal the identity of a participant will not be included in any publications or presentations. The data were analyzed in total.

Case abstracting was performed by a research assistant trained in data collection. Cases of DM were documented retrospectively by studying the medical records from January 1 , 2010 to December 31, 2010. Incident cases were collected by assessing the date of diagnosis. The cases diagnosed for the first time during the study period were included as incident cases.

The following diagnostic criteria were used: (1) Diabetes was defined as a fasting plasma glucose (FPG) concentration of $\geq$ $126 \mathrm{mg} / \mathrm{dL}$ or previous first diagnosis of DM within the same time period. Impaired fasting glucose and normoglycemia were defined as a FPG concentration of 110-126 mg/dL and < $110 \mathrm{mg} / \mathrm{dL}$, respectively; ${ }^{13)}$ (2) When criterion (1) was not met, we relied on the notes written by doctors elsewhere given that the first diagnosis by the other physician was within the same time period.

Data files that fed into the Excel ver. 2010 spreadsheet were transformed to IBM SPSS ver. 20.0 (IBM Co., Armonk, NY, USA) for statistical analysis. The crude and specific incidence rates were calculated. The incidence rate was presented for different age groups (i.e., 5 -year intervals), and confidence intervals for the proportions were estimated.

The crude incidence rates were calculated by considering the population of Ajman in 2010 and newly diagnosed DM cases. The DM cases and total population were arranged into different age groups with 5-year intervals to separately calculate age specific DM incidence rates for men and women.

\section{RESULTS}

A total of 158 new DM cases were diagnosed during 2010; 102 of these cases were Emiratis residents and the remaining cases were other nationalities. Among the 102 Emiratis cases, there was only 1 type $1 \mathrm{DM}$ case, and the remaining 101 type $2 \mathrm{DM}$ cases were included in the estimation of incidence rate. The age range was $23-78$ years.

The overall incidence rate of DM cases observed among those aged $\geq 20$ years was $4.8 / 1,000$ person-years (PY). In the present study, 35 patients (34.7\%) were men and 66 patients (65.3\%) were women, indicating female predominance. The gender specific incidence rate was 3.3/1,000 PY for men and $6.3 / 1,000 \mathrm{PY}$ for women. The age specific incidence rate for men and women are shown in Figure 1. The incidence rates in men and women were almost similar until the age of 39 years.

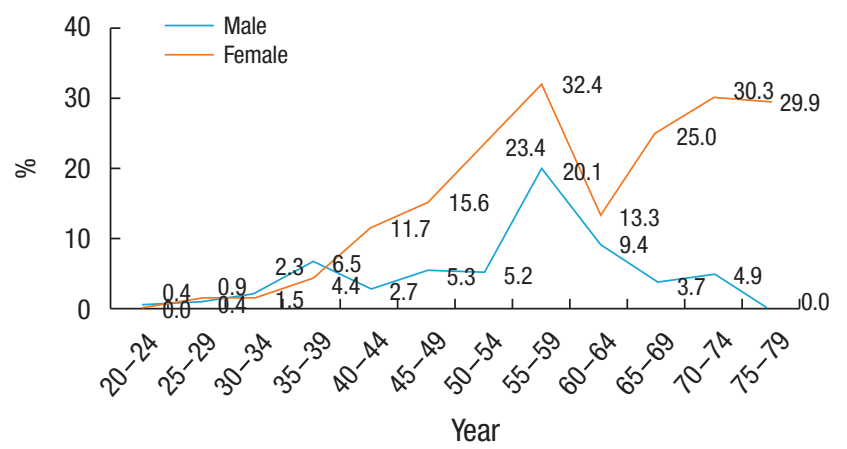

Figure 1. Age specific diabetes mellitus incidence rates for males and females in Ajman Emirate.

However, women who were $\geq 40$ years showed a higher incidence rate than men. The highest incidence rate for both genders (men, 23.4/1,000 PY; women, 32.4/1,000 PY) was observed in the 55-59 years age group, and then a downward trend was observed.

\section{DISCUSSION}

In this study, we evaluated the incidence of DM among Emirati residents because they constitute a more stable population than expatriates. Future studies involving this population will reflect changes in the epidemiology of this problem that can be linked to lifestyle, socioeconomic, or health service factors.

According to the present study, a similar type 2 DM incidence were observed both among Emirati men and women in Ajman, UAE in the age group of 20-39 years, and a female preponderance in the incidence rate of $\mathrm{DM}$ in the later age groups. The incidence of DM was 4.4/1,000 PY in 2005 according to a study from the United Kingdom (UK). ${ }^{15)}$ The crude incidence rate of type $2 \mathrm{DM}$ was 515/100,000 (or 5.15/1,000 PY) in 2010 based on more recent data from the UK. ${ }^{16)}$ According to this study, the incidence of DM increased with age, and was similar among men and women up to 40 years of age. After 40 years of age, men had a higher incidence rate of DM than women. The gender specific incidence rate for men and women was $4.86 / 1,000 \mathrm{PY}$ and 4.31/1,000 PY, respectively. ${ }^{15)}$ An overall DM incidence rate of 10/1,000 PY with a male predominance was observed in a study from the United States of America; using data from the New York City Community Health Survey, the incidence rates were 11/1,000 PY and 9/1,000 PY in 2008 for men and women, respectively. ${ }^{17)}$ The overall incidence of DM was 6.3/1,000 PY in 2011 based on the report, "Diabetes in Canada," and a male predominance was observed in the gender-specific rates (6.8/1,000 PY in men compared to 5.7/1,000 $\mathrm{PY}$ in women in the year 2009). ${ }^{18)} \mathrm{A}$ cohort study conducted over a period of 2000-2009 reported an overall incidence rate of DM in China was 9.5/1,000 PY with a male predominance ( $11 \%$ men vs. $6.2 \%$ women). ${ }^{19)}$ According to a previous study in 


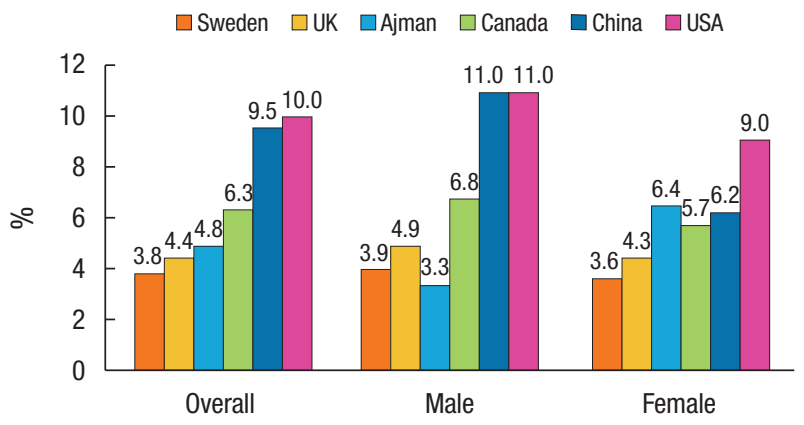

Figure 2. Gender-wise crude incidence rate for diabetes in the different countries.

the year 2000-2009, the overall (20-79 years of age) incidence rate of DM in Taiwan was 11.6/1,000 PY. ${ }^{20)}$ In a report from Sweden, ${ }^{21)}$ the incidence rate (20-100 years of age) in men and women were nearly similar (3.92/1,000 PY and 3.64/1,000 PY in men and women, respectively). The comparison of crude incidence rates in different countries is provided in Figure 2.

An age-wise increasing trend in the age specific rates of DM was observed for both men and women in Sweden. However, only the 10-year age specific incidence rate was available, and the highest rate was observed in the 70-79 years age group (9.94/1,000 PY and 7.77/1,000 PY for men and women, respectively. The age specific incidence rates of DM were $0.20,0.54$, 2.37, 4.68, and 7.46/1,000 PY for men and 0.29, 0.70, 1.71, 3.57, and 6.51/1,000 PY for women in the 20-29, 30-39, 40-49, 50-59, and 60-69 years age groups, respectively. ${ }^{21)}$ The age specific incidence rate of DM in Canada was comparable with the present findings (Figures 3,4 ). The rate of DM was almost similar at the age of 40 years in the present study. The peak incidence rate of DM was observed in the 55-59 years age group and then a downward trend in the incidence rate of DM was observed. In Canada, a steady increase in the incidence rate of DM was observed with increasing age, and the incidence rate in women was much higher in Ajman than in Canada. A variation in the DM epidemiological pattern was observed in the available data in developing compared to developed countries. According to the present study, DM appears to affect mostly younger participants (range, 44-64 years), while in developing countries, the majority of diabetic patients were $>64$ years of age. ${ }^{4)}$ The higher incidence rate of DM observed among women compared to men after the age of 40 years in this study was incompatible with data from the UK. A further study is needed to investigate the possible related factors (i.e., hormonal, dietary, lifestyle, and social factors) that can restrict the physical activity of older women. Both men and women have a nearly similar global prevalence of DM with slightly higher rates in men $<60$ years of age and women at older age, greater than 60 years. $\left.{ }^{4}\right)$

It is worth noting that, according to the International Diabetes Federation, ${ }^{7)}$ the estimated percentage of undiagnosed diabetic patients in Middle-Eastern high-income countries (i.e.,

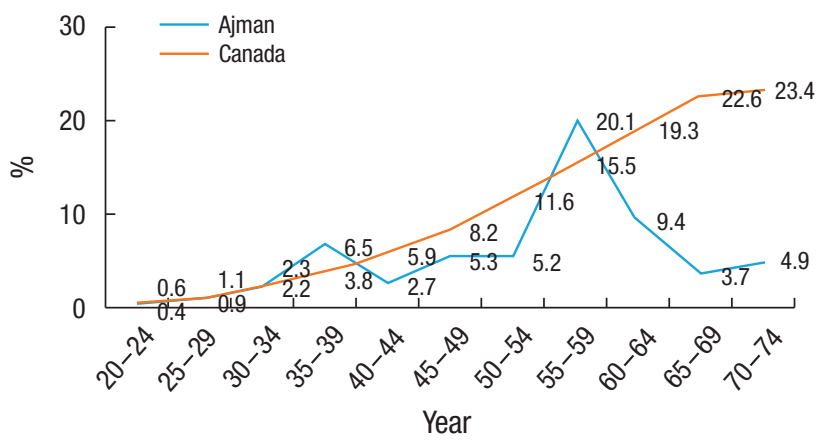

Figure 3. Age specific rates of diabetes mellitus in Ajman and Canada-male.

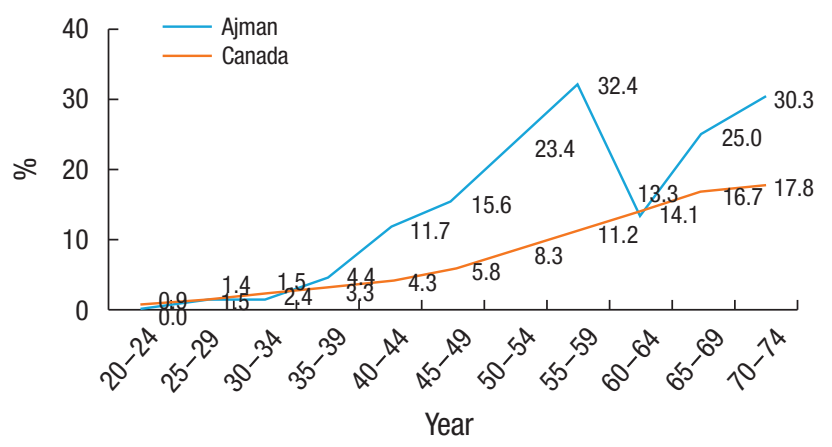

Figure 4. Age specific rates of diabetes mellitus in Ajman and Canada-female.

UAE) was $40.6 \%$ in the year 2011. Therefore, the actual incidence of DM is about $40 \%$ higher than what was observed in this study. An important finding in this study was that the incidence of DM started to increase after the age of 30 years, which implies that earlier screening, rather than the currently recommended screening at 45 years of age for people without risk factors by the American Diabetic Association, ${ }^{22)}$ is necessary for this disease in the UAE. In this study, we have provided evidence to support recommendations by the UAE National Diabetes Committee, ${ }^{13)}$ which is included in the Periodic Health Check Up Program ${ }^{23)}$ to start screening for DM in all individuals in the UAE at the age of $\geq 30$ years. Other researchers ${ }^{24)}$ from the UAE explored the need for such a modification to the current American Diabetes Association guidelines based on their finding of a low prevalence rate of undiagnosed DM (1.5\%) among low risk individuals (age, $<45$ years; body mass index, $<25 \mathrm{~kg} / \mathrm{m}^{2}$ ). Certainly, the final decision about the age to initiate screening for DM is affected by cost-effectiveness and health system capacity factors in addition to the incidence/prevalence of the disease. ${ }^{25)}$ We recommend future studies to be conducted in these areas.

\section{Limitations}

The incident cases of DM were collected from 5 PHCs at Shaikh Khalifa Hospital and Gulf Medical College Hospital in Ajman, UAE. It is possible that the incidence rate of DM was underestimated in this study because Emirati residents at other hospitals 
were not considered. Even with this limitation, we can conclude that the incidence rate of DM was higher than in the UK and Sweden.

\section{Conclusions}

The highest incidence rate of DM was observed in the 55-59 year age group (men, 23.4/1,000 PY; women, 32.4/1,000 PY). The incidence rate among men was much lower than in women in the $>59$ years age groups.

\section{CONFLICT OF INTEREST}

No potential conflict of interest relevant to this article was reported.

\section{REFERENCES}

1. Shaw JE, Sicree RA, Zimmet PZ. Global estimates of the prevalence of diabetes for 2010 and 2030. Diabetes Res Clin Pract 2010;87:4-14.

2. Waly MI, Essa MM, Ali A, Al-Shuhaibi YM, Al-Farsi YM. The global burden of type 2 diabetes: a review. Int J Biol Med Res 2010;1:326-9.

3. United Nations General Assembly. United Nations Resolution 61/225: world diabetes day [Internet]. Brussels: International Diabetes Federation; 2006 [cited 2015 Sep 2]. Available from: http://www.idf.org/sites/ default/files/UN\%20Resolution\%20on\%20World\%20Diabetes\%20 Day\%20of\%20Dec\%202006.pdf.

4. Wild S, Roglic G, Green A, Sicree R, King H. Global prevalence of diabetes: estimates for the year 2000 and projections for 2030. Diabetes Care 2004;27:1047-53.

5. Danaei G, Finucane MM, Lu Y, Singh GM, Cowan MJ, Paciorek CJ, et al. National, regional, and global trends in fasting plasma glucose and diabetes prevalence since 1980: systematic analysis of health examination surveys and epidemiological studies with 370 country-years and 2.7 million participants. Lancet 2011;378:31-40.

6. Alavi NM, Ghofranipour F, Ahmadi F, Emami A. Developing a culturally valid and reliable quality of life questionnaire for diabetes mellitus. East Mediterr Health J 2007;13:177-85.

7. International Diabetes Federation. IDF diabetes atlas [Internet]. 5th ed. Brussels: International Diabetes Federation; 2012 [cited 2013 Sep 2]. Available from: http://www.idf.org/diabetesatlas.

8. Centers for Disease Control and Prevention. National diabetes fact sheet 2011 [Internet]. Atlanta (GA): U.S. Department of Health and Human Services, Centers for Disease Control and Prevention; 2011 [cited 2013 Sep 2]. Available from: http://www.cdc.gov/diabetes/ pubs/pdf/ndfs_2011.pdf.

9. American Heart Association. National diabetes fact sheet 2013 [Internet]. Dallas (TX): American Heart Association; 2013 [cited 2013 Sep 2]. Available from: http://www.heart.org/idc/groups/heartpublic/@ wcm/@sop/@smd/documents/downloadable/ucm_319585.pdf.

10. Mathers CD, Vos T, Lopez AD, Salomon J, Ezzati M. National burden of disease studies: a practical guide Edition 2.0 [Internet]. Geneva: Global Program on Evidence for Health Policy, World Health Organization;
2011 [cited 2013 Sep 2]. Available from: http://www.who.int/healthinfo/nationalburdenofdiseasemanual.pdf.

11. International Diabetes Federation. The IDF diabetes atlas: a summary of the figures and key findings. 5th ed. Brussels: International Diabetes Federation; 2011.

12. International Diabetes Federation. Diabetes atlas [Internet]. 3rd ed. Brussels: International Diabetes Federation; 2006 [cited 2013 Sep 2]. Available from: https://www.idf.org/sites/default/files/Diabetes\%20 Atlas\%203rd\%20edition.pdf.

13. The UAE National Diabetes Committee. National diabetes guidelines: United Arab Emirates 2009. [place unknown]: The UAE National Diabetes Committee; 2009.

14. Saadi H, Carruthers SG, Nagelkerke N, Al-Maskari F, Afandi B, Reed R, et al. Prevalence of diabetes mellitus and its complications in a population-based sample in Al Ain, United Arab Emirates. Diabetes Res Clin Pract 2007;78:369-77.

15. Gonzalez EL, Johansson S, Wallander MA, Rodriguez LA. Trends in the prevalence and incidence of diabetes in the UK: 1996-2005. J Epidemiol Community Health 2009;63:332-6.

16. Holden SH, Barnett AH, Peters JR, Jenkins-Jones S, Poole CD, Morgan CL, et al. The incidence of type 2 diabetes in the United Kingdom from 1991 to 2010. Diabetes Obes Metab 2013;15:844-52.

17. Tabaei BP, Chamany S, Driver CR, Kerker B, Silver L. Incidence of selfreported diabetes in New York City, 2002, 2004, and 2008. Prev Chronic Dis 2012;9:E114.

18. Public Health Agency of Canada. Diabetes in Canada: facts and figures from a public health perspective 2011 [Internet]. Ottawa: Public Health Agency of Canada; 2011 [cited 2013 Sep 9]. Available from: http:// www.phac-aspc.gc.ca/cd-mc/publications/diabetes-diabete/factsfigures-faits-chiffres-2011/index-eng.php.

19. Shang X, Li J, Tao Q, Li J, Li X, Zhang L, et al. Educational level, obesity and incidence of diabetes among Chinese adult men and women aged 18-59 years old: an 11-year follow-up study. PLoS One 2013;8:e66479.

20. Jiang YD, Chang CH, Tai TY, Chen JF, Chuang LM. Incidence and prevalence rates of diabetes mellitus in Taiwan: analysis of the 2000-2009 Nationwide Health Insurance database. J Formos Med Assoc 2012;111: 599-604.

21. Thunander M, Petersson C, Jonzon K, Fornander J, Ossiansson B, Torn C, et al. Incidence of type 1 and type 2 diabetes in adults and children in Kronoberg, Sweden. Diabetes Res Clin Pract 2008;82:247-55.

22. American Diabetes Association. Standards of medical care in diabetes-2013. Diabetes Care 2013;36(Suppl 1):S11-66.

23. Fares HH, Mohammad F, Al Awar S, Al Kabi A, Blaila BB. Periodic health check-up recommendation. Abu Dhabi: Ministry of Health, United Arab Emirates; 2011.

24. Saadi H, Nagelkerke N, Al-Kaabi J, Afandi B, Al-Maskari F, Kazam E. Screening strategy for type 2 diabetes in the United Arab Emirates. Asia Pac J Public Health 2010;22(3 Suppl):54S-59S.

25. World Health Organization. Screening for type 2 diabetes: report of a World Health Organization and International Diabetes Federation meeting [Internet]. Geneva: Marketing and Dissemination, World Health Organization; 2003 [cited 2013 Sep 10]. Available from: http:// www.who.int/diabetes/publications/en/screening_mnc03.pdf. 